\title{
CORAL AMADOR: EFEITOS DE UMA PROPOSTA DE INTERVENÇÃO FONOAUDIOLÓGICA
}

\section{Amateur choir: the effect of speech therapy intervention}

\author{
Camila Miranda Loiola ${ }^{(1)}$, Leslie Piccolotto Ferreira ${ }^{(2)}$
}

\begin{abstract}
RESUMO
Objetivo: verificar os efeitos de uma proposta de intervenção fonoaudiológica com base na prática educativa, por meio de avaliação de fonoaudiólogos, professores de canto e dos próprios coristas amadores participantes, analisando, em momento pré e pós-intervenção fonoaudiológica, os parâmetros de respiração, projeção e tessitura vocal na voz cantada. Métodos: o programa teve o referencial teórico de ZABALA (1998) sobre a prática educativa. Dez cantores de coral amador responderam a um questionário de caracterização e realizaram gravações da extensão vocal e canto, pré e pós-intervenção. Durante seis encontros, foi abordado o aquecimento vocal, anatomia e fisiologia da voz cantada, bem-estar vocal, respiração e propriocepção da voz. As gravações foram analisadas por juízes fonoaudiólogos e professores de canto, que avaliaram a respiração, projeção e tessitura vocal. Os coristas, sem acesso às gravações, realizaram auto-avaliação dos mesmos parâmetros. Resultados: avaliação dos juízes: tessitura vocal teve mais alterações positivas, seguida da respiração e projeção vocal. Todos os parâmetros tiveram mudanças significantes $(p<0,01)$. Fonoaudiólogos analisaram a tessitura vocal mais de acordo com o esperado, professores de canto consideraram a projeção, e a respiração apresentou dados equivalentes estatisticamente. Os resultados por sujeito mostraram que dois cantores apresentaram melhoras em todos os parâmetros analisados e sete deles, em pelo menos dois deles. Os cantores perceberam melhoras em todos os aspectos. Conclusão: a intervenção teve efeitos positivos nos coristas e mostrou a necessidade de realizar estudos que avaliem o processo em si, a fim de se valorizar a atuação do fonoaudiólogo na voz cantada.
\end{abstract}

DESCRITORES: Voz; Treinamento da Voz; Qualidade da Voz

\section{INTRODUÇÃO}

A maioria dos corais, formados em igrejas, comunidades, escolas, faculdades e clubes, é composta por cantores amadores ${ }^{1}$. O indivíduo que ingressa

(1) Fonoaudióloga; Afiliada ao Programa de Estudos de PósGraduados em Fonoaudiologia da Pontifícia Universidade Católica de São Paulo, PUC-SP, São Paulo, SP, Brasil; Mestre em Fonoaudiologia pela Pontifícia Universidade Católica de São Paulo; Doutoranda em Fonoaudiologia pela Pontifícia Universidade Católica de São Paulo.

(2) Fonoaudióloga; Professora Titular da Graduação e PósGraduação em Fonoaudiologia da Pontifícia Universidade Católica de São Paulo, PUC-SP, São Paulo, SP, Brasil; Coordenadora e Docente do Curso de Especialização em Fonoaudiologia - Voz da Coordenadoria Geral de Especialização, Aperfeiçoamento e Extensão da Pontifícia Universidade Católica de São Paulo, COGEAE-PUC/SP, São Paulo, SP, Brasil; Doutora em Distúrbios da Comunicação Humana pela Universidade Federal de São Paulo.

Conflito de interesses: inexistente nessa modalidade, em geral, o faz pelo prazer de cantar, e não utiliza o canto para o seu sustento. Além disso, muitas vezes o indivíduo que pratica o canto desconhece as técnicas necessárias e os cuidados que devem ser tomados com a voz.

Um coral é composto de indivíduos dotados de vozes com características diversas, que apresentam diferenças determinadas por nuances acústicas ${ }^{2}$. Dessa forma, o canto coral deve buscar a harmonização das vozes para resultar em boa sonoridade do grupo. Portanto, além da participação do regente, torna-se fundamental a atuação do fonoaudiólogo para realizar um trabalho de educação e preparação vocal dos cantores de coral para que com isso possam cumprir as exigências que essa modalidade musical requer, sem prejudicar suas próprias vozes e o resultado sonoro final do grupo.

Como o coral apresenta particularidades que o diferenciam de outras modalidades, alguns parâmetros de voz cantada devem ser considerados nos 
indivíduos que se inserem nesse tipo de atividade. A respiração, a projeção e a tessitura vocal são alguns deles. A respiração é fundamental para todo cantor, especialmente para o corista amador, que geralmente não tem aprendizado prévio de canto. A consciência respiratória é uma das ferramentas que pode contribuir para o processo de ensino/ aprendizagem musical no coral ${ }^{3 .}$ A projeção vocal também deve ser trabalhada, pois geralmente no coro o repertório é executado a capella, o que torna necessário ter uma projeção adequada para atingir o público. Quanto à tessitura vocal, apesar de sua importância no coral, poucos estudos foram realizados e novas pesquisas devem ser incentivadas para o enriquecimento do tema ${ }^{4}$.

A literatura consultada a respeito de cantores ${ }^{5-11}$ evidencia uma preocupação em se desenvolverem pesquisas com o objetivo de levantar as características vocais e os sintomas percebidos por essa população. Dentre elas, destaca-se o estudo epidemiológico que analisou 143 questionários respondidos por cantores de coral amador e concluiu que os sintomas relacionados a distúrbios vocais mais mencionados foram: pigarro/secreção, rouquidão e tosse com secreção ${ }^{12}$. As causas prováveis para o aparecimento desses sintomas, na opinião dos entrevistados, foram gripe, uso intensivo da voz e alergia. Tal pesquisa reforça a necessidade do acompanhamento fonoaudiológico com cantores de coral amador, uma vez que o conhecimento sobre a atribuição das causas dos sintomas mencionados pode contribuir para a ampliação de propostas de intervenção que englobem ações promotoras de saúde.

Os estudos que abordam a voz de cantores são frequentes na literatura. Foi realizado um levantamento da produção bibliográfica sobre o tema voz cantada no Brasil no período de 2005 a 2007 e encontraram um total de 117 trabalhos ${ }^{13}$. Verificouse que o maior número de pesquisas tem sido realizado com cantores de coral e a forma mais comum de apresentação desses trabalhos acontece em anais de Congresso. Nesse sentido, as autoras ressaltaram que essa forma de publicação apresenta limites, pois como em anais são publicados apenas os resumos dos trabalhos podem deixar dúvidas acerca do método ou da totalidade da pesquisa. Dentre as pesquisas, a ênfase é dada na aplicação de técnicas e/ou exercícios vocais para a avaliação pré e pós imediato, sem se aprofundarem em uma intervenção com o acompanhamento do profissional junto aos cantores. Com relação à atuação do fonoaudiólogo, as autoras salientaram que ainda existe uma grande dificuldade de se escrever sobre a prática na área de voz cantada, visto que foram encontrados apenas cinco estudos de intervenção fonoaudiológica com o canto. Essa realidade é diferente na literatura internacional, uma vez que pesquisas que abordam o trabalho com cantores são comuns em diferentes países ${ }^{14-18}$.

Nessa direção, acredita-se que a produção científica na área de voz cantada ainda carece de trabaIhos de intervenção fonoaudiológica que visem ao estabelecimento de ações de promoção da saúde para essa população. Portanto, a pesquisa em questão se propôs a avançar em duas vertentes: por um lado, ampliar a intervenção para além da aplicação isolada dos exercícios de aquecimento vocal e por outro proporcionar uma atuação com maior número de encontros, visando buscar mais do que os efeitos imediatos de uma proposta, uma possibilidade de atentar os cantores para uma mudança de atitude frente ao uso da voz cantada. Para tanto, buscou-se realizar um programa de intervenção em diferentes encontros semanais, com exercícios de aquecimento vocal associados a noções de anatomia e fisiologia da voz aplicada ao canto, discussões sobre saúde vocal, trabalho com respiração e propriocepção da voz em cantores de coral. Por acreditar que a prática fonoaudiológica precisa ser refletida como um processo de educação em saúde, a estrutura didática dessa proposta de intervenção foi norteada por uma reflexão sobre a prática educativa de Zabala $^{19}$. Esse educador preconizou que, para que haja a produção efetiva do conhecimento, devem ser realizadas relações interativas, com diferentes conteúdos que não se compartimentam e que proporcionem a formação integral do indivíduo, respeitando a sua diversidade.

O objetivo deste estudo, portanto, foi verificar os efeitos de uma proposta de intervenção fonoaudiológica com base na prática educativa, por meio de avaliação de fonoaudiólogos, professores de canto e dos próprios coristas amadores participantes, analisando, em momento pré e pós-intervenção fonoaudiológica, os parâmetros de respiração, projeção e tessitura vocal na voz cantada.

\section{MÉTODOS}

Esta pesquisa de caráter prospectivo, exploratório e descritivo apresentou com os seguintes procedimentos:

\section{Seleção dos sujeitos}

O grupo que participou da pesquisa é um coral amador cujos integrantes não precisam ter como pré-requisito um conhecimento musical apurado para fazer parte do mesmo. O repertório é variado e em geral composto por canções populares. 


\section{Critérios de inclusão}

As condições para participar da pesquisa foram: não apresentar problema de saúde auto-referido e/ ou comprometimento das vias aéreas superiores e inferiores nos dias das gravações e participar de todas as etapas de coleta de dados da pesquisa. As condições de saúde dos participantes foram checadas pela pesquisadora no momento da gravação por meio de entrevista e observação aos coristas.

Os cantores que aceitaram participar voluntariamente da pesquisa somaram um total de 10 participantes.

\section{Procedimentos}

Após assinarem o termo de consentimento, os sujeitos receberam um questionário, que foi respondido individualmente levantou os dados pessoais dos integrantes, a classificação vocal, o tempo de participação no coral, as horas dedicadas aos ensaios, a formação musical, as queixas e conhecimentos e hábitos sobre aspectos da saúde vocal. Dessa forma, foi traçado um perfil do grupo: foi representado por seis integrantes do sexo feminino (quatro sopranos e dois contraltos) e quatro do sexo masculino (um tenor e três baixos), com a faixa etária que variou de 17 a 67 anos (média de 40,3 anos). Com relação ao tempo no coral, três cantores participam a menos de um ano, cinco deles entre um a nove anos e dois há mais de dez anos. A média de tempo dedicado aos ensaios foi de cinco horas e 30 minutos semanais. Entre as queixas na voz cantada, foram citados: $50 \%$ dificuldade em atingir tons agudos e graves, $40 \%$ dificuldade para manter a voz até o final da frase musical, $30 \%$ cansaço ao cantar, $30 \%$ ar na voz e $20 \%$ referiram rouquidão.

\section{Coleta da amostra}

A coleta da amostra para análise se deu por meio de gravações de voz feitas individualmente em uma sala silenciosa. Foram realizadas duas coletas do material descrito, porém em períodos diferentes. A primeira gravação (gravação 1) ocorreu no momento inicial da pesquisa, pré-intervenção fonoaudiológica. A segunda gravação (gravação 2) ocorreu depois de três semanas, após o término dos encontros propostos pela pesquisadora em horário e local previamente definido entre os membros.

Os dados de voz foram registrados diretamente no notebook da marca Toshiba Mobile Intel(R), por meio do programa de gravação de som Sound Forge 8.0, com o microfone profissional headset da marca AKG, modelo C-420. Este foi posicionado a aproximadamente cinco centímetros da boca do sujeito, que ficou de pé durante as gravações, uma vez que esta geralmente é a postura adotada nos ensaios do grupo.

Foram registradas, sem realizar sessão de aquecimento vocal prévio, as seguintes emissões: tessitura vocal, com a emissão da vogal /a/ seguindo as notas fornecidas pelo piano: foi apresentada um nota inicial no piano, Do3 para mulheres e Do2 para homens, seguindo então de $1 / 2$ em $1 / 2$ tom em direção às frequências agudas até o limite de cada cantor, e em seguida descendo às freqüências mais graves, novamente até onde o cantor conseguisse emitir; e um segundo registro, a amostra de canto de uma música da preferência de cada sujeito, realizada a capella. Ressalta-se que cada sujeito escoIheu a canção desejada para gravar para ter garantida a execução correta da mesma. Além disso, as diferentes canções escolhidas não prejudicaram a análise dos dados, uma vez que, nessa pesquisa, foram realizadas avaliações intrassujeitos.

\section{Intervenção fonoaudiológica}

A pesquisadora promoveu um trabalho fonoaudiológico com os cantores, subsidiada pela proposta de ensino e aprendizagem de o educador Antoni Zabala ${ }^{19}$, que traz uma reflexão sobre a prática educativa, fornecendo um referencial teórico para esse processo. $O$ autor afirma que o termo "conteúdo", que se refere àquilo que se pretende aprender, não deve ser restrito aos conteúdos de caráter cognitivo, mas deve também abranger todos aqueles que possibilitem o desenvolvimento de outras capacidades, motoras, afetivas, de relação interpessoal e inserção social.

Sendo assim, o autor agrupa os conteúdos segundo sejam conceituais (conceitos e princípios), procedimentais (regras, técnicas, métodos, habilidades, estratégias, procedimentos) ou atitudinais (valores, atitudes e normas). Tais conteúdos, por mais específicos que sejam, estão sempre associados e mostram que a aprendizagem não se compartimenta. Vale ressaltar ainda a importância da interação professor-aluno no processo de ensino e aprendizagem e do espaço educativo como uma organização social que precisa ser construída com respeito à diversidade dos sujeitos.

Acredita-se, portanto, que essa proposta pode auxiliar na prática fonoaudiológica em suas ações educativas, que devem ser refletidas como um processo de educação em saúde, considerando sempre a função social dessas ações, como os sujeitos aprendem e principalmente que a ação deve contar com situações problematizadoras, direcionadas à formação integral e ao respeito à diversidade dos sujeitos envolvidos ${ }^{20}$.

Baseada no referencial teórico exposto, na literatura específica consultada e também a partir da 
experiência da própria fonoaudióloga e pesquisadora, foi preparado um programa de intervenção fonoaudiológica. Foram realizados seis encontros semanais, com a duração de uma hora cada, o que totalizou a carga horária de seis horas de intervenção fonoaudiológica com o grupo.

Os exercícios propostos no programa de aquecimento vocal foram orientados pela pesquisadora para que fosse garantida a execução correta da proposta. O roteiro construído pela pesquisadora incluiu exercícios de alongamento, respiração, exercícios vocais além de questões advindas dos próprios cantores no decorrer dos encontros com o grupo. Foram realizadas explicações sobre a importância do aquecimento vocal para o cantor, além de explanações sobre os objetivos de cada exercício proposto. A cada encontro, a pesquisadora retomou os temas abordados no encontro anterior e esclareceu as dúvidas dos cantores, para seguir com a proposta.

\section{Edição do material}

Os dados coletados nas gravações 1 e 2 foram editados pelo programa Sound Forge 8.0. A gravação da tessitura vocal foi mantida na íntegra para registrar o desempenho dos cantores na prova solicitada. Do outro registro efetuado, ou seja, a música escolhida pelos sujeitos, foi editado um trecho de 30 a 40 segundos de duração, a partir da segunda estrofe cantada pelo participante. Optouse por desconsiderar a primeira estrofe da canção para garantir que o cantor estivesse mais à vontade e integrado com a música cantada no momento da gravação.

O material editado foi organizado em um CD e cada faixa correspondeu a uma amostra vocal solicitada. As faixas do CD continham as gravações pré e pós intervenção fonoaudiológica editadas aos pares referentes a cada sujeito, e randomizadas, de maneira que os juízes não identificassem a ordem das gravações apresentadas.

\section{Análise dos dados}

Os dados coletados foram analisados de acordo com a avaliação perceptivo-auditiva da voz realizada por juízes que ouviram o CD com as amostras de tessitura vocal e de canto. Além disso, foi realizada uma auto-avaliação dos cantores, a partir de questionário respondido por eles após a gravação 2.

Seis juízes fizeram parte da banca de avaliadores: três fonoaudiólogas especialistas em voz, com experiência em voz cantada de no mínimo três anos e três professores de canto, também com experiência, que foram convidados a participar da pesquisa. Os juízes receberam uma carta de instruções, o Termo de Consentimento Livre e Esclarecido, o material editado em CD e um protocolo de avaliação perceptivo-auditiva da voz cantada, construído pela pesquisadora. Coube registrar no protocolo dizer se as gravações vocais estavam iguais ou diferentes para cada sujeito. Cada juiz deveria justificar sua resposta, baseado nas categorias apresentadas: respiração, projeção (para as amostras de canto) e a tessitura vocal.

Após as avaliações realizadas, foi estipulado que as análises que identificaram melhoras nos parâmetros pós intervenção eram consideradas de acordo com o esperado para essa pesquisa. De forma inversa, se os juízes, ao analisarem as gravações, tivessem assinalado que a amostra vocal ou a tessitura que estava melhor correspondia à primeira gravação (pré intervenção), este seria um resultado não esperado, pois a hipótese era de que todos os parâmetros alcançariam melhoras após a intervenção.

Os coristas, sem terem acesso às gravações, realizaram auto-avaliação dos mesmos parâmetros analisados pelos juízes.

Esta pesquisa foi aprovada pelo Comitê de Ética da Pontifícia Universidade Católica de São Paulo (PUC-SP) sob o no 136/2008.

As avaliações foram comparadas e foi também efetuada a análise estatística dos dados obtidos. Para a análise estatística foi usado, primeiramente, um teste qui-quadrado para detectar se a intervenção fonoaudiológica teve efeito. Buscou-se também comparar as avaliações realizadas pelos Fonoaudiólogos e pelos Professores de Canto. Dessa forma, foi usada a técnica de Equações de Estimação Generalizada, obtendo a razão de chances (odds-ratio) para se detectar diferença na avaliação entre Fonoaudiólogos e Professores de Canto.

A razão de chances deve ser interpretada da seguinte forma: o Intercepto é a chance de uma avaliação feita por fonoaudiólogo ter sido como o esperado e a razão de chances para o Professor de Canto significa quantas vezes maior é a chance desse juiz ter avaliado como esperado em relação ao fonoaudiólogo.

\section{RESULTADOS}

A Tabela 1 apresenta os dados numéricos referentes às avaliações dos juízes nos parâmetros selecionados. Esta representa o número de respostas dos fonoaudiólogos e professores de canto que foram de acordo com o esperado, bem como o índice de porcentagem. Tem-se, portanto, que cada parâmetro avaliado dos dez sujeitos teve 30 avaliações de cada grupo de juízes (três 
Tabela 1 - Avaliação dos juízes: porcentagem de avaliações esperadas e não esperadas referentes aos parâmetros de respiração, projeção e tessitura vocal

\begin{tabular}{|c|c|c|c|c|c|c|c|c|c|c|c|c|c|c|c|c|}
\hline & \multicolumn{5}{|c|}{ Fonoaudiólogos } & \multicolumn{5}{|c|}{ Professores de canto } & \multicolumn{5}{|c|}{ TOTAL } & \multirow{3}{*}{ p-valor } \\
\hline & \multicolumn{5}{|c|}{ De acordo com o esperado } & \multicolumn{5}{|c|}{ De acordo com o esperado } & \multicolumn{5}{|c|}{ De acordo com o esperado } & \\
\hline & Sim & $\%$ & Não & $\%$ & Total & Sim & $\%$ & Não & $\%$ & Total & Sim & $\%$ & Não & $\%$ & Total & \\
\hline Respiração & 19 & 63,3 & 11 & 37 & 30 & 22 & 73,3 & 8 & 26,7 & 30 & 41 & 68,3 & 19 & 31,7 & 60 & $<0,01^{*}$ \\
\hline Projeção & 17 & 56,7 & 13 & 43 & 30 & 23 & 76,7 & 7 & 23,3 & 30 & 40 & 66,7 & 20 & 33,3 & 60 & $0,01^{*}$ \\
\hline Tessitura & 24 & 80 & 6 & 20 & 30 & 19 & 63,3 & 11 & 36,7 & 30 & 43 & 71,7 & 17 & 28,3 & 60 & $<0,01^{*}$ \\
\hline TOTAL & 60 & 66,7 & 30 & 33 & 90 & 64 & 71,1 & 26 & 28,9 & 90 & 124 & 68,9 & 56 & 31,1 & 180 & \\
\hline
\end{tabular}

Teste Qui-Quadrado

*significante

fonoaudiólogos e três professores de canto), com o total de 60 análises dos seis juízes, para cada parâmetro. No total, foram levantados os dados numéricos e percentuais de resultados esperados e não esperados entre todos os juízes, para cada parâmetro e em todos os parâmetros em conjunto. Os dados numéricos das auto-avaliações dos cantores não foram inseridos na tabela, uma vez que 100\% das análises dos mesmos foi de acordo com o esperado.

Percebe-se que a intervenção surtiu efeito na respiração $(p<0,01)$. Entretanto, não houve diferença significante (Tabela 2 ) entre a avaliação do fonoaudiólogo e do professor de canto $(p=0,41)$.

Com relação à projeção vocal, vê-se que a intervenção surtiu efeito significante $(p=0,01)$. Além disso, a chance de um professor de canto ter avaliado como o esperado foi 2,51 vezes maior do que de um fonoaudiólogo ter avaliado como o esperado $(p=0,01$, Tabela 2$)$.

Nota-se também que a intervenção teve efeito na tessitura $(p<0,01)$. Além disso, a chance de um professor de canto ter avaliado como o esperado é 0,43 vezes maior do que o fonoaudiólogo $(p=0,02$, Tabela 2).

A Tabela 2, portanto, representa a razão de chances do professor de canto ter avaliado os parâmetros de acordo com o esperado, em comparação com o fonoaudiólogo, representado pelo intercepto (grupo base para a análise estatística).

Observa-se, na Tabela 1, que em relação à efetividade da proposta de intervenção nos parâmetros de respiração, projeção e tessitura vocal, todos os resultados apresentaram significância estatística. Ao se comparar a avaliação de fonoaudiólogos e professores de canto (Tabela 2), a análise mostrou que a respiração obteve um equilíbrio entre as análises, a projeção vocal foi avaliada com maior índice de respostas de acordo com o esperado entre os professores de canto e a tessitura vocal apresentou maior índice de respostas de acordo com o esperado entre os fonoaudiólogos.

Foi realizada também a análise dos resultados por sujeito. Para tanto, considerou-se que o sujeito apresentou índice de melhora em determinado parâmetro se pelo menos dois dos três juízes de cada grupo respondesse de acordo com o esperado $\mathrm{O}$ gráfico apresentado mostra, portanto, $\mathrm{O}$ número de sujeitos que melhoraram em pelo menos dois parâmetros (ou seja, dois ou três deles) e o número de cantores que melhoraram em todos os parâmetros, ou seja, nos três avaliados, na opinião dos juízes (Figura 1).

Tabela 2 - Estimativa de regressão logística para como foi esperado para os parâmetros de respiração, projeção e tessitura vocal

\begin{tabular}{lcccccccccc}
\hline & \multicolumn{4}{c}{ Intercepto } & \multicolumn{4}{c}{ Professores de canto } \\
\cline { 2 - 11 } & Estimativa & $\begin{array}{c}\text { Erro } \\
\text { Padrão }\end{array}$ & p-valor & $\begin{array}{c}\text { razão de } \\
\text { chances }\end{array}$ & IC (95\%) & Estimativa & $\begin{array}{c}\text { Erro } \\
\text { Padrão }\end{array}$ & p-valor & $\begin{array}{c}\text { razão de } \\
\text { chances }\end{array}$ & IC (95\%) \\
\hline Respiração & 0,547 & 0,511 & 0,28 & 1,73 & $(0,63-4,7)$ & 0,465 & 0,565 & 0,41 & 1,59 & $(0,53-4,82)$ \\
Projeção & 0,268 & 0,29 & 0,36 & 1,31 & $(0,74-2,31)$ & 0,921 & 0,36 & $0,01^{*}$ & 2,51 & $(1,24-5,09)$ \\
Tessitura & 1,39 & 0,30 & $<0,01$ & 4 & $(2,22-7,23)$ & $-0,84$ & 0,36 & $0,02^{*}$ & 0,43 & $(0,21-0,87)$ \\
\hline
\end{tabular}

Técnica de Equações de Estimação Generalizada

*significante 


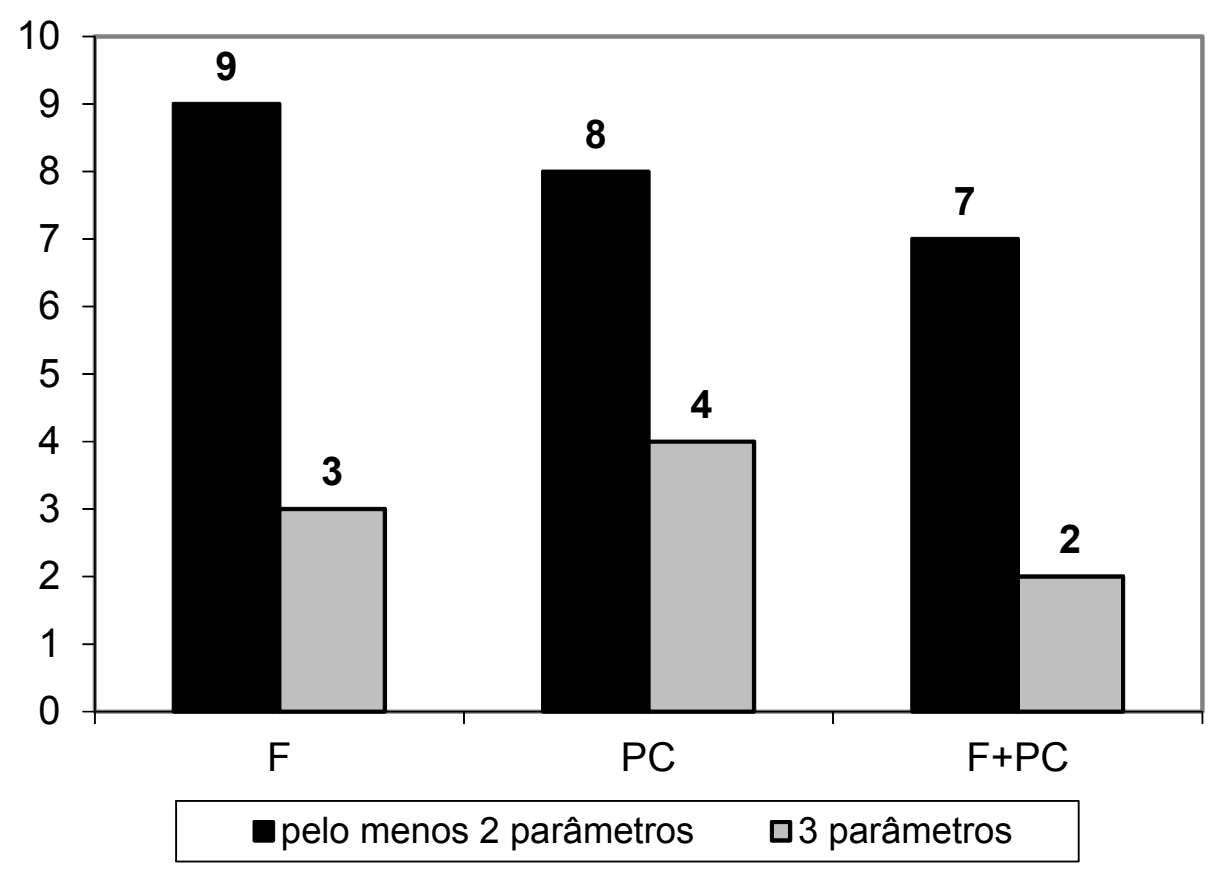

Figura 1 - Distribuição dos sujeitos que foram considerados pelos juízes (F - Fonoaudiólogos; PC Professores de Canto) como tendo melhorado em pelo menos dois ou em todos os três parâmetros trabalhados

Observa-se que apenas dois sujeitos ( $\mathrm{S} 1$ e S10) melhoraram em todos os parâmetros na opinião dos fonoaudiólogos e dos professores de canto. Porém, ao analisar pelo menos dois dos três parâmetros, esse número aumentou para sete sujeitos.

\section{DISCUSSÃO}

A presente pesquisa objetivou verificar os parâmetros de respiração, projeção e tessitura vocal em cantores de um coral amador, após a aplicação de uma proposta de intervenção fonoaudiológica. Os resultados indicaram que o parâmetro que mais promoveu efeitos positivos entre os coristas foi a tessitura, em seguida a respiração e, por último, a projeção vocal. A partir desses resultados, julgouse necessário discutir a análise geral dos dados, bem como a comparação das avaliações dos juízes fonoaudiólogos e dos professores de canto e a propriocepção dos cantores. Além disso, realizouse uma reflexão acerca da análise do índice de melhoras dos parâmetros por sujeito. Todos os resultados apresentados foram discutidos à luz da proposta de ensino e aprendizagem ${ }^{19}$, de forma a propor um espaço para a ação fonoaudiológica enquanto prática educativa.

Ao classificar qual parâmetro obteve mudanças mais significantes após a intervenção, a ampliação da tessitura vocal foi o aspecto que apresentou maior concordância entre os juízes. Tal resultado pode ser justificado pelo fato da forma de análise da tessitura ter sido mais objetiva. Ao ouvir as amostras, os juízes poderiam contar o número de notas que cada cantor produziu e, dessa forma tornou-se mais fácil identificar qual delas estava mais extensa e com melhor qualidade. A pesquisa mostrou que uma intervenção fonoaudiológica pode interferir positivamente em um parâmetro essencial e específico da voz cantada, tal como constatado em outro com cantores que realizavam treinamento vocal ${ }^{21}$. Os achados coincidem com a literatura internacional que também verificou expansão da extensão vocal após um período de treinamento vocal com cantores ${ }^{15,16}$. Tais pesquisas, porém, ofereceram um período maior de intervenção, o que provavelmente contribuiu para resultados mais consistentes entre os cantores. Entre as pesquisas nacionais, observou-se um estudo que levantou os valores (em semitons) de extensão vocal de cantores de coros evangélicos amadores e comparou com os dados de literatura, porém sem realizar nenhum trabalho vocal com o grupo ${ }^{1}$. A presente pesquisa representou um avanço nesse sentido, uma vez que comparou o desempenho dos cantores, de forma qualitativa, antes e depois de uma proposta de intervenção fonoaudiológica. Além disso, realizou um aprofundamento no estudo da tessitura vocal, ou seja, o número de notas produzidas com qualidade 
vocal. As próprias autoras acima citadas conceituaram que "tessitura" em italiano significa "tecido", "trama" e, portanto, representa o conjunto de notas usadas no canto com absoluta comodidade e qualidade musical. Esse enfoque é de maior interesse para cantores e regentes, pois nem todos os sons emitidos pelo cantor em sua extensão vocal têm qualidade para serem utilizados no canto. Sendo assim, atendeu à sugestão de pesquisa anterior ${ }^{4}$, que ressaltou a necessidade de se investigar a melhora da tessitura vocal em cantores de coral amador. Esse parâmetro é muito importante para cantores e regentes de coral, pois uma vez que o cantor tem a sua tessitura mais ampla, seu aproveitamento no canto é melhor e as melodias são executadas com qualidade e sem esforço. O regente, por sua vez, pode explorar repertórios diversificados, de maior complexidade e pode também trabalhar com a estética do canto com melhor eficácia, sem se preocupar com o alcance das notas. Sendo assim, reforça-se a ideia da importância do trabalho integrado entre fonoaudiólogos e regentes de coral para potencializar as capacidades do grupo e garantir um melhor resultado sonoro e artístico.

A melhora nos padrões de respiração foi o segundo parâmetro mais evidente. O resultado corrobora os achados de outras pesquisas ${ }^{22,23}$, que também encontraram melhoras na respiração de cantores (coral amador e lírico, respectivamente) após a intervenção aplicada. Um bom apoio respiratório é fundamental para o cantor, uma vez que favorece um aumento da pressão subglótica e do fluxo máximo de ar sem sobrecarregar a laringe ${ }^{3,24-27}$. Os autores salientaram também a possibilidade de colocar as estruturas musculares em posição inspiratória durante a expiração para proporcionar o aumento do gradil costal, proposta essa enfatizada pela pesquisadora durante todo o trabalho de respiração realizado com os coristas nos encontros. Também a autora da pesquisa citada acima ${ }^{22}$, essa atitude é importante e foi salientada durante os exercícios de aquecimento vocal realizados em sua pesquisa com cantores de coral amador.

Embora tenha sido um parâmetro de menor percepção de mudanças positivas, quando comparado aos demais, a projeção vocal também sofreu alterações, uma vez que os juízes identificaram que alguns cantores tiveram melhor desempenho nesse aspecto. Associado ao apoio respiratório, esse parâmetro auxilia na boa produção da voz cantada com vocalização mais eficiente ${ }^{23,27}$. Também contribui como recurso de interpretação e dinâmica, tal como percebeu o cantor S3, que relatou que conseguiu "experimentar a voz em diferentes intensidades com qualidade". Um fato que chamou a atenção sobre a percepção do corista é que ele mencionou não apenas a projeção, como também a qualidade vocal. Com isso, verificou-se que a intervenção foi ampla e foi possível atingir aspectos além daqueles trabalhados nos encontros. Exercícios que envolvem o trabalho com a projeção vocal estão presentes em propostas de treinamento e aquecimento vocal ${ }^{28,29}$. Especificamente para o canto coral representa um recurso importante, pois os coristas em geral executam suas canções a capella e necessitam projetar suas vozes para atingir o público.

Observou-se, portanto, que todos os parâmetros abordados sofreram mudanças após a intervenção. Porém, tais mudanças não foram unânimes entre os juízes, uma vez que nem todos os cantores melhoraram em todos os aspectos. Na percepção dos próprios cantores, por sua vez, todos os parâmetros sofreram melhoras. Esse resultado mostra que a propriocepção do sujeito não é suficiente para demonstrar os efeitos de uma intervenção fonoaudiológica, pois o participante, satisfeito com a proposta e os novos conceitos adquiridos, sempre percebe mudanças em sua própria voz. Porém, essa percepção não garante que tenha de fato ocorrida a mudança. Pode-se exemplificar esse fenômeno com a avaliação da cantora S2 que, ao falar de sua projeção vocal, afirmou estar "boa" na gravação pós-intervenção fonoaudiológica, porém nenhum dos juízes identificou melhoras. Dessa forma, evidencia-se a importância do ouvido experiente do juiz para perceber os efeitos na voz, pois pesquisas que utilizam apenas a propriocepção como forma de análise podem gerar resultados mascarados.

Nessa direção, algumas considerações podem ser feitas quanto aos resultados obtidos utilizando como base teórica a reflexão sobre a prática educativa ${ }^{19}$. Pesquisadoras fonoaudiólogas, ao assumirem a postura adotada pelo autor, destacaram que o trabalho fonoaudiológico dirigido à promoção das questões vocais deve intervir nas mudanças das condições de vida e de trabalho dos envolvidos, e criar oportunidades para que esses possam ser agentes de sua saúde e bem-estar, com otimização de suas próprias habilidades ${ }^{20}$. Do ponto de vista do educador citado, o conteúdo que se deve aprender abrange outras capacidades além daquelas de caráter puramente cognitivo. Com isso, ele traz a classificação dos conteúdos conceituais, procedimentais e atitudinais e mostra que os mesmos devem estar sempre associados. Com base nessa reflexão, a pesquisadora observou, ao comparar o relato de auto-percepção dos sujeitos com a avaliação perceptivo-auditiva dos juízes, que os conteúdos conceituais foram adquiridos, os 
procedimentos e habilidades foram compreendidos e aprendidos, porém ainda não ocorreu uma internalização para a mudança de atitude frente aos novos conteúdos, uma vez que alguns parâmetros ainda não foram alterados em alguns coristas. Segundo o autor, para que o processo de ensino-aprendizagem seja efetivo e completo, é necessário atingir os três níveis. Durante toda a proposta, buscouse contemplar esses três conteúdos para que a intervenção representasse uma ação educativa e promovesse um novo olhar para o trabalho fonoaudiológico com a voz cantada. Contudo, nota-se que os conteúdos atitudinais não foram passíveis de um controle da pesquisadora para que ocorressem com os coristas, uma vez que uma mudança de atitude depende, fundamentalmente, do próprio sujeito. Para exemplificar, pode-se citar a auto-avaliação da cantora S9 que, ao falar de sua respiração após a intervenção fonoaudiológica, relatou que encontrou "dificuldades em função da gravidez de oito meses, porém havia percebido melhoras ao manter as notas durante os ensaios". Nesse caso, a corista conseguiu perceber alguma mudança com relação ao apoio respiratório mesmo sem haver consenso na avaliação dos juízes, uma vez que dois dos três fonoaudiólogos não identificaram melhoras nesse aspecto. Na opinião dos professores de canto, porém, a melhora na gravação pós-intervenção de fato ocorreu. A mudança percebida pela cantora ocorreu nos ensaios habituais do coro, fora do espaço da intervenção. Dessa forma, sugere-se que a cantora esteja em fase de aquisição de uma nova atitude frente aos padrões de respiração e está transferindo os conteúdos aprendidos para um contexto maior, mesmo com uma limitação fisiológica (gravidez).

Outro aspecto que pode justificar a não totalidade de mudanças refere-se ao número e à duração dos encontros oferecidos ao grupo. Apesar de não ter sido objetivo da pesquisa, durante um levantamento da opinião dos cantores quanto aos aspectos positivos e negativos da proposta, os mesmos referiram que o único fator negativo foi o tempo restrito para a execução dos exercícios e dos novos conceitos adquiridos. Esse fato evidencia a importância de se realizar um trabalho continuado com cantores de coral, para que não haja apenas uma ação isolada, sem retorno dos resultados em médio e longo prazo. Possivelmente, com um tempo maior de trabalho, as habilidades das quais se referiram as autoras ${ }^{20}$ poderiam ser potencializadas a fim de se estabelecerem novos comportamentos diante das questões da voz cantada.

Com relação à análise do número de sujeitos que melhoraram a respiração, a projeção e a tessitura vocal, na opinião dos juízes, verificou-se que a proposta de intervenção fonoaudiológica foi efetiva para gerar mudanças em pelo menos dois dos três parâmetros avaliados. A comparação entre o grupo de fonoaudiólogos e professores de canto indicou um equilíbrio entre as avaliações realizadas. Ao analisar a melhora em todos os parâmetros, os fonoaudiólogos indicaram três dos coristas (S1, S4 e S10), os professores de canto, quatro deles (S1, $\mathrm{S} 5$, S8 e $\mathrm{S10}$ ) e esse número diminuiu para dois participantes (S1 e S10) ao associar a avaliação de ambos os juizes (fonoaudiólogos e professores de canto). Acredita-se que esses sujeitos tenham conseguido inserir uma nova atitude frente aos conteúdos oferecidos e com isso conseguiram bons resultados em suas vozes. Observou-se também que esses indivíduos tiveram participação ativa no decorrer dos encontros, referiram realizar as atividades em casa e não faltaram em nenhum encontro. A participação do cantor no processo é fundamental para que de fato ocorra uma mudança.

Ao comparar os dois grupos de juízes em suas avaliações, constatou-se que os fonoaudiólogos consideraram que o parâmetro que sofreu maiores mudanças positivas foi a tessitura vocal, seguida da respiração e projeção vocal. Entre os professores de canto, a projeção vocal foi o que mais modificou-se positivamente, acompanhada da respiração e, por último, a tessitura. $\mathrm{O}$ fato dos professores de canto terem identificado um menor índice de melhoras na tessitura vocal pode indicar que os mesmos possuem uma avaliação mais rigorosa desse parâmetro. O professor de canto trabalha diretamente com esse aspecto ao realizar a classificação vocal de um cantor de coral ou no trabalho com escalas musicais, portanto, possivelmente apresenta uma exigência maior para a análise. A avaliação da respiração e da projeção vocal também apresentou diferenças entre os dois grupos de juízes, no entanto foi mais equilibrada. Isso indica uma concordância quanto às análises desses parâmetros, uma vez que ambos os profissionais trabalham diretamente com essas questões na voz cantada.

Além da análise dos resultados, também devem ser feitas algumas considerações quanto ao método da pesquisa em questão. $O$ primeiro ponto que chamou a atenção foi a forma de apresentação dos conteúdos da proposta. Tal como foi explicitado, a pesquisadora buscou apresentar uma proposta de intervenção mais ampla e com a intenção de realizar com os coristas uma ação com enfoque na questão do ensino e aprendizagem de acordo com Zabala ${ }^{19}$. Adotada essa postura, a pesquisadora não se limitou a apresentar uma série de exercícios e também acrescentou ao processo conteúdos referentes à anatomia e fisiologia aplicada à voz cantada, saúde vocal, respiração e o 
trabalho corporal. Sendo assim, o conteúdo programático apresentado na proposta contemplou vários níveis de conhecimento na área de voz cantada e propiciou aos coristas um alto grau de rendimento e conscientização quanto a esses aspectos básicos. Ao selecionar questões teórico-práticas sobre anatomia e fisiologia dos órgãos fonatórios, noções de saúde vocal, conhecimento da dinâmica respiratória, além das vocalizações e a técnica vocal propriamente dita (com exercícios vocais para articulação, projeção e aquecimento vocal), a pesquisadora buscou estabelecer um processo de ensinoaprendizagem que permitiu o "estabelecimento de um padrão de propriocepção refinado e capaz de realizar ajustes vocais para uma boa emissão cantada" ${ }^{3}$.

Nesse sentido, a pesquisadora utilizou como método em sua proposta de intervenção, retomar os temas discutidos e as práticas realizadas no início de cada encontro, antes de dar continuidade aos novos conteúdos. Partiu-se do principio de que um conteúdo está sempre associado a outros e, portanto, eles se relacionam para que haja um aprendizado efetivo. Dessa forma, os cantores tiveram um feedback do trabalho realizado e foi aberto um espaço para reflexão, retomada dos conteúdos vivenciados anteriormente e inserção desses aos novos, fato que favoreceu uma prática não compartimentada no processo de aprendizagem.

Outra postura adotada pela pesquisadora que a princípio gerou efeitos positivos e representa um diferencial na proposta foi utilizar o recurso de auto-percepção durante toda a intervenção. Essa estratégia atentou os coristas para sua própria voz e seu corpo, atitude que os mesmos mencionaram não ter até então. Acredita-se que, ao conhecer melhor o próprio corpo, sua tensões, bem como a sua voz, o cantor pode ter um maior domínio de seu aparelho fonador e pode ter a noção dos aspectos que precisa melhorar. Estudo que utilizou exercícios proprioceptivos corporais e vocais em sua intervenção reitera essa afirmação, uma vez que encontrou resultados positivos para a percepção e o controle das tensões musculares durante o canto, advindos de tais exercícios ${ }^{23}$.

Um aspecto importante, no tocante metodológico, refere-se à maneira como a proposta de intervenção fonoaudiológica foi construída. Inicialmente, a pesquisadora desenvolveu um esboço de todos os seis encontros, com os objetivos de cada sessão. Porém, buscou reorganizá-los a cada reunião com o grupo de maneira que o encontro seguinte se conectasse ao trabalho iniciado na sessão anterior e pudesse também responder à demanda apresentada pelos próprios coristas. Chegada a metade do trabalho, a pesquisadora realizou um grupo focal, em que foram discutidos os aspectos positivos e negativos da proposta até aquele momento. Abriu-se também um espaço para que os cantores discorressem sobre suas expectativas e o rendimento dos encontros, bem como sugestões de temas para as últimas reuniões do grupo. Dessa forma, foi considerada a aprendizagem de maneira singular e respeitou-se as experiências de cada indivíduo e essa postura também é destacada como auxiliar para o sucesso de uma ação educativa ${ }^{19}$. Vale ressaltar, portanto, que nenhuma proposta de intervenção pode ser vista como uma "receita" a ser seguida à risca, mas sim como possibilidades de aplicação frente à demanda encontrada no grupo a ser trabalhado. Deve-se lembrar que em todo processo de aprendizagem reside uma subjetividade que deve ser levada em consideração de maneira a atender a cada um dos sujeitos de maneira singular e, ao mesmo tempo, satisfazer às necessidades mais gerais do grupo em questão.

Associada à ideia da singularidade e com o intuito de promover a interação o interesse de todos os participantes, a proposta foi organizada de maneira dinâmica, associando teoria e prática a todos os conteúdos oferecidos, desde o primeiro encontro. Considera-se fundamental que haja vivências dinâmicas nas primeiras aulas de um processo de intervenção para depois suscitar um trabalho de maior introjeção ${ }^{23}$. A pesquisadora, por sua vez, optou por mesclar as vivências com a teoria para que houvesse um maior rendimento do grupo. Tal procedimento trouxe efeitos positivos, pois o grupo manteve o interesse sem perder o foco durante todo o processo.

Acredita-se, portanto, que o trabalho realizado com os coristas amadores mostrou-se satisfatório, de maneira geral, uma vez que proporcionou mudanças positivas nos parâmetros de respiração, projeção e tessitura vocal. No entanto, muitos outros aspectos foram levantados a partir dessa proposta e foi aberto um espaço para a reflexão e questionamento sobre a forma de analisar os achados de pesquisas que se propõem a desenvolver uma intervenção fonoaudiológica com cantores. Essa pesquisa, portanto, incentiva estudos que possam não apenas comparar a voz pré e pós-intervenção fonoaudiológica, mas avaliar o processo em si, que pode trazer contribuições tão ou mais valiosas que os resultados vocais que são esperados nessas propostas. Tal análise que é comumente negligenciada em pesquisas na área de voz e merece um aprofundamento, tanto em questões metodológicas quanto práticas.

Sugere-se que, para os próximos estudos, a questão do aumento da carga horária seja considerada para que os aspectos abordados possam ser 
aprimorados e os conteúdos atitudinais, incorporados à vida dos sujeitos. Espera-se que a pesquisa aqui apresentada abra caminho para outros estudos que enfoquem a intervenção fonoaudiológica na voz cantada para garantir um crescimento na qualidade das produções científicas e da própria prática. Dessa forma, o fonoaudiólogo poderá ganhar mais espaço no trabalho com cantores e poderá realizar um trabalho integrado entre os diversos profissionais da música vocal.

\section{CONCLUSÕES}

Concluiu-se que a proposta de intervenção fonoaudiológica com cantores de coral amador gerou efeitos positivos nos parâmetros de respiração, projeção e tessitura vocal, em contexto de voz cantada. De maneira geral, os juízes consideraram que $o$ aspecto que mais apresentou mudanças de acordo com o esperado foi a tessitura vocal, seguida da respiração e, por último, a projeção vocal. Ao comparar os grupos de juízes entre si, constatouse que fonoaudiólogos perceberam melhores resultados nos parâmetros de tessitura vocal e professores de canto, na projeção vocal. Na autoavaliação, todos os cantores fizeram referencia a melhora nos três parâmetros avaliados.

Com relação ao número de sujeitos que apresentou mudanças positivas na voz cantada, verificou-se que a maioria deles, na avaliação dos juízes, apresentou mudanças em pelo menos dois dos três aspectos avaliados.

\begin{abstract}
Purpose: to check the effects of a speech therapy intervention, based on the educational practice, by the assessment of speech and language pathologists, singing teachers and amateur choral singers themselves, analyzing the parameters of breathing, projection and vocal range profile in singing voice, pre and post speech therapy intervention. Methods: the program was the theoretical framework of Zabala (1998) on educational practice. Ten amateur choral singers responded to a characterization questionnaire and conducted recordings of vocal range and singing, pre and post intervention. During six meetings, we approached warm up, anatomy and physiology as for the singing voice, vocal health, breathing and voice perception. The recordings were analyzed by judges (speech therapists and singing teachers) that assessed breathing, projection and vocal range profile. The choristers, without access to the recordings, made self-assessment of those parameters. Results: evaluation of judges: vocal range had more positive changes, followed by breathing and vocal projection. All parameters had significant changes $(p<0.01)$. Speech therapists analyzed the vocal range more in line with expectations, singing teacher considered the projection, and breathing data showed results statistically equivalent. The results by subject showed that two singers had improvements in all parameters and seven of them, at least, in two of the parameters. The singer's perception showed improvements in all aspects. Conclusion: the intervention had positive effects on the choir and showed the need for studies that may evaluate the process itself, in order to enhance the speech therapist acting on the singing voice.
\end{abstract}

KEYWORDS: Voice; Voice Training; Voice Quality

\section{REFERÊNCIAS}

1. Costa PJBM, Ferreira KI, Camargo ZA, Pinho SMR. Extensão vocal de cantores de coros evangélicos amadores. Rev. CEFAC. 2006; 8(1):96-106.

2. Behlau M, Rehder MI. Higiene vocal para o canto coral. vol.1. Rio de Janeiro: Revinter; 2008.

3. Amato RF. O canto coral como prática sóciocultural e educativo-musical. Opus Goiânia. 2007; 13(1):75-96.
4. Rocha TF, Amaral FP, Hanayama EM. Extensão vocal de idosos coralistas e não coralistas. Rev. CEFAC. 2007; 9(2):248-54.

5. Cruz TLB, Gama ACC, Hanayama EM. Análise da extensão e tessitura vocal do contratenor. Rev. CEFAC. 2004; 6(4):423-8.

6. Leite GCA, Assumpção R, Campiotto AR, Andrada e Silva, MA. O canto nas igrejas: o estudo do uso vocal dos coralistas e não-coralistas. Rev Dist Comun. 2004; 16(2):229-39. 
7. Ribeiro LR, Hanayama EM. Perfil vocal de coralistas amadores. Rev. CEFAC. 2005; 7(2):252-66.

8. Nishimura CM, Camargo ZA, Cordeiro GF, Pinho SMR. Características vocais do canto japonês nos gêneros Enka e Mudo Enka. Rev. CEFAC. 2006; 8(4):493-500.

9. Rehder MIBC, Behlau MS. Perfil vocal de regentes de coral do estado de São Paulo. Rev. CEFAC. 2008; 10(2):206-17.

10. Quintela AS, Leite G, Cristina I, Daniel RJ Práticas de aquecimento e desaquecimento vocal de cantores líricos. HU Revista. 2008; 34(1):41-6.

11. Handam $A L$, Deeb $R$, Tohme RA, Rifai $H$, Husseini S, Fuleihan N. Vocal technique in a group of middle eastern singers. Folia Phoniatr Logop. 2008; 60(4):217-21.

12. Gonçalves TAC. Correlação entre sintomas vocais e sua possíveis causas em um grupo de coralistas da cidade de São Paulo. [dissertação]. São Paulo (SP): Pontifícia Universidade Católica de São Paulo; 2007.

13. Andrada e Silva MA, Barbosa RA. A voz cantada. In: Oliveira IB, Almeida AAF, Raize T, organizadores: Voz profissional: produção científica da Fonoaudiologia brasileira. 3. ed. Suplemento especial da Revista da Sociedade Brasileira de Fonoaudiologia, 2008. [CD rom].

14. Broaddus-Lawrence PL, Treole K, McCabe R, Allen RL, Toppin $L$. The effects of preventive vocal hygiene education on the vocal hygiene habits and perceptual vocal characteristics of training singers. $J$ Voice. 2000; 14(1):58-71.

15. LeBorgne WD, Weinrich BD. Phonetogram changes for trained singers over a nine-month period of vocal training. J Voice. 2002; 16(1):37-43. 16. Mendes AP, Rothman HB, Sapienza C, Brown WS. Effects of vocal training on the acoustic parameters of the singing voice. J Voice. 2003; 17(4):529-43.

17. Amir O, Amir N, Michaeli O. Evaluating the influence of warmup on singing voice quality using acoustic measures. J Voice. 2005; 19:252-60.
18. Mendes AP, Brown WS, Sapienza C, Rothman HB. Effects of vocal training on respiratory kinematics during singing tasks. Folia Phoniatr Logop. 2006; 58(5):363-77.

19. Zabala A. A prática educativa: como ensinar. Porto Alegre: ArtMed; 1998.

20. Ferreira LP, Chieppe D. Quando as prática fonoaudiológicas são educativas... Rev. Dist Comun. 2005; 17(1):123-6.

21. Sulter AM, Schutte HK, Miller DG. Differences inn phonetogram features between male and female subjects with and without vocal training. $\mathrm{J}$ Voice. 1995; 9(4):363-77.

22. Espiresz S. Performance de coralistas amadores em situação pré e pós-aquecimento vocal: Uma avaliação perceptivo-auditiva. [monografia]. São Paulo (SP): Pontifícia Universidade Católica de São Paulo; 2004.

23. Mello EL. Voz do cantor lírico: efeitos da aplicação de um Programa de Desenvolvimento da Coordenação Motora baseado em Piret e Béziers. Rev Soc Bras Fonoaudiol. 2009; 14(3):352-61.

24. McCoy S. Breath management: gender-based differences in classical singers. Folia Phoniatr Logop. 2005; (5-6):246-54.

25. Andrade SR, Fontoura DR, Cielo CA. Interrelações entre fonoaudiologia e canto. Rev Música Hodie. 2007; 7(1):83-98.

26. Sonninen A, Laukkanen AM, Karma K, Hurme P. Evaluation of support in singing. J Voice. 2005; 19(2):223-37.

27. Thorpe $C$. Patterns of breath support in projection of the singing voice. J. Voice 2001; 15(1):86-104.

28. Nordenberg M, Sundberg J. Effect on LTAS of vocal loudness variation. Logoped Phoniatr Vocol. 2004; 29:183-91.

29. Cassol M, Bós AJG. Canto coral melhora sintomas vocais em idosos saudáveis. Rev Bras Ciências do Envelh Humano. 2006; 3(2):113-22.

DOI: 10.1590/S1516-18462010005000113

RECEBIDO EM: 07/12/2009

ACEITO EM: 12/07/2010

Endereço para correspondência:

Camila Miranda Loiola.

Rua Jaceguai, 465 ap. 2501

São Paulo - SP

CEP: 01315-010

E-mail: milaloiola@yahoo.com.br 